J. Reprod. Fert. (1975) 45, 73-82

\title{
RELATIONSHIP BETWEEN THE ELECTRICAL ACTIVITY OF THE OVIDUCT AND THE UTERUS OF THE RABBIT IN VIVO
}

\author{
Y. RUCKEBUSCH \\ Laboratoire de Physiologie, Ecole Nationale Vétérinaire, Toulouse, France*
}

(Received 11th December 1974)

\begin{abstract}
Summary. The electrical activity of the whole genital tract of the rabbit was recorded by means of chronically implanted electrodes after section of the uterotubal junction on one side. When the junction was intact, the activity of the isthmus and that of the proximal uterine horn occurred almost simultaneously, but uterine activity decreased after the junction was cut. During the preovulatory phase and also after administration of HCG, synchronous activity due to adrenergic drugs, smoke or oxytocin persisted on both sides of the uterotubal junction. Hypersensitivity of the isthmus and the proximal segment of the uterine horn was recorded on the cut side after ovariectomy. The concept of a local control mechanism in the region of the uterotubal junction with a positive control of the uterus by the oviduct is suggested.
\end{abstract}

\section{INTRODUCTION}

Recent studies of the electrical activity of the oviduct and the uterus throughout the oestrous cycle in the intact cow (Ruckebusch \& Bayard, 1975) have indicated that, in addition to the hormonal status of the animal, the region of the uterotubal junction is of paramount importance in the regulation of uterine activity. The present report of a similar study, involving unilateral section of the uterotubal junction in the rabbit, is an attempt to clarify any possible relationship between the patterns of electrical activity of the isthmus and the uterus. The study was designed to compare activity of the intact side versus the cut side before and after ovulation and after ovariectomy.

In the rabbit, a dense network of adrenergic nerve terminals (Owman et al., 1966 ) is located on the ampullary-isthmic junction (Talo \& Brundin, 1971) and uterine responses are easily elicited by hypogastric nerve stimulation. These responses are similar to those elicited by adrenaline (Setekleiv, 1964). Since neither adrenalectomy nor administration of atropine (White et al., 1974) prevents the responses (apnoea, bradycardia and vasoconstriction) evoked by nasopharyngeal stimulation with cigarette smoke (Allen, 1929), the smoke

\footnotetext{
* Postal address: Ecole Nationale Vétérinaire, 23, chemin des Capelles, 31076 Toulouse Cédex,
} France. 
reflex may be presumed to act via the adrenergic nerves. For this reason this reflex was considered useful for studying stimulation of the utero-oviducal musculature in rabbits.

Oestrogens and progestins are recognized as playing essential roles in normal tubal transport (Harper, 1966) and myometrial behaviour (Schofield, 1955). They strongly influence the patterns of contraction. The high frequency of contractions in the oviduct seen under oestrogen dominance (Mattos \& Coutinho, 1971) is damped during the luteal phase (Aref \& Hafez, 1973) and also after injection of progesterone (Higgs \& Moawad, 1974). Furthermore, oestrogen withdrawal after ovariectomy increases ampullary contractions (Boling \& Blandau, 1971). Maximal contractility occurs in the uterus during the preovulatory phase, and a 'myometrial block' is established during the luteal phase (Porter, 1968) and pregnancy (Greenwald, 1963; Csapo \& Takeda, 1965). The activity of the oviduct and the uterus was therefore studied after ovulation and after ovariectomy.

The injection of noradrenaline and adrenaline in anaesthetized rabbits initiates contractions of the oviduct, but isoprenaline causes relaxation (Longley et al., 1968). The degree of response of adrenergic alpha and beta receptors in the tubal isthmus depends upon the hormonal status (Howe \& Black, 1973), as does the response of the uterus to oxytocin. During the preovulatory phase or under oestrogen dominance, different areas of the genital tract are highly sensitive to adrenergic drugs.

This work presents recordings of the spontaneous electrical activity of the genital tract of the rabbit after unilateral section of the uterotubal junction, and examines changes induced by adrenaline, noradrenaline and oxytocin, and the smoke reflex under oestrogen or progesterone dominance and after ovariectomy during long-term experiments.

\section{MATERIALS AND METHODS}

Investigations were carried out on twelve Fauve de Bourgogne sexually mature does weighing about $3 \mathrm{~kg}$ each. Under pentobarbitone anaesthesia, pairs of electrodes, $80 \mu \mathrm{m}$ in diameter, were inserted for each oviduct (i) on the ampulla, at about $2 \mathrm{~cm}$ from the fimbria, (ii) on the ampullary-isthmic junction and (iii) on the isthmus, at about $1 \mathrm{~cm}$ from the uterotubal junction. Electrodes were inserted on each uterine horn as follows: (iv) one pair at 1 or $2 \mathrm{~cm}$ from the uterotubal junction, (v) another pair at $4 \mathrm{~cm}$ from this same junction, and the last one (vi) on the distal segment of the uterine horn at $2 \mathrm{~cm}$ from the cervix. Additional pairs of electrodes were also fixed on the cervix and on the vagina at $1 \mathrm{~cm}$ from the cervix. The total number of electrodes inserted was limited to ten pairs per subject by eliminating pairs on the ampullary-isthmic junctions and on the uterus. In all animals, section of the uterotubal junction was performed on the left side at the time of electrode implantation.

Bipolar electromyograms were obtained on a ten-channel polygraph $(R C$ coupling, time constant $0 \cdot 1 \mathrm{sec}$ ) in daily recording sessions of 3 to $4 \mathrm{hr}$ for periods of about 3 weeks. All the rabbits were ovariectomized 2 weeks after surgery allowing 1 further week for observations of the effect of this and response 
to drugs. Three additional intact rabbits were used as controls for description of the patterns of normal electrical activity.

Oestrogen dominance was considered to exist when strong activity persisted 5 days after surgery. In $3 / 12$ rabbits, the activity was reinforced at this time by an injection of $40 \mu \mathrm{g}$ oestradiol benzoate. The luteal phase was considered to be developed after ovulation was induced on the 10th day after surgery by injection of 100 i.u. HCG (Ayerst Laboratories, New York) into the marginal ear vein (Harper, 1963). Nasal inhalation of cigarette smoke was achieved by blowing smoke through a tube onto the nose for periods of 4 to $5 \mathrm{sec}$. Preliminary studies

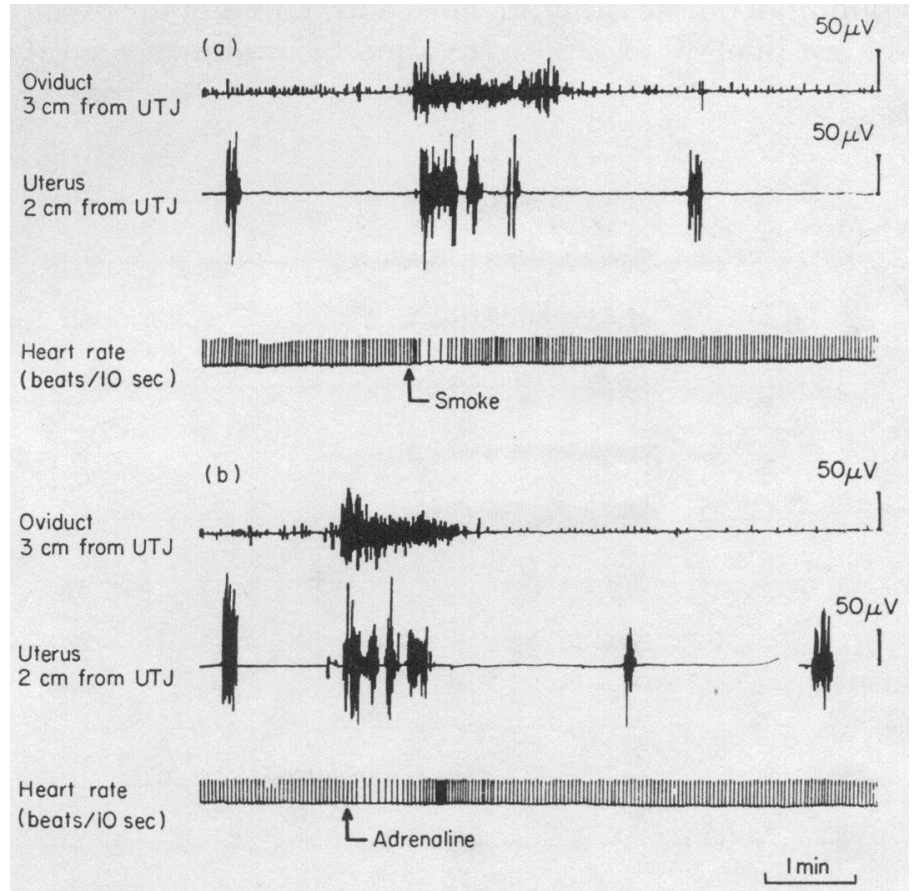

TExT-FIG. 1. Comparative effects of adrenaline and smoke on the activity of the intact uterotubal junction (UTJ) of the rabbit. (a) Nasal stimulation by cigarette smoke induced a burst of spikes on the isthmus and the proximal segment of the uterus as well as bradycardia. (b) Injection of $5 \mu \mathrm{g}$ adrenaline; note the similarity of the effect to that recorded in (a).

had shown that activation of the uterotubal junction and accompanying bradycardia resulting from this were equal to that seen, depending on the responsiveness of individuals, after injection, of 2.5 to $5 \mu \mathrm{g}$ adrenaline (U.V.A., Paris) $/ \mathrm{kg}$ (Text-fig. 1). Adrenaline $(5 \mu \mathrm{g} / \mathrm{kg}$ ) or $10 \mu \mathrm{g}$ noradrenaline $/ \mathrm{kg}$ (Levophed: Winthrop Laboratories, Dijon) and 0.01 i.u. synthetic oxytocin (Ciba, Paris) were also injected via the marginal ear vein on a randomized duplicate basis. Oxytocin was injected $15 \mathrm{~min}$ after the noradrenaline or adrenaline injections which were given between the 5 th and 10th day after surgery (preovulatory phase), from $72 \mathrm{hr}$ to 5 days after HCG (luteal phase) and from 2 to 7 days after ovariectomy. Phentolamine ( $1 \mathrm{mg} / \mathrm{kg}$; Regitine: Ciba, Paris) 
was occasionally injected, by way of the marginal ear vein, 20 min before the adrenergic drugs and the smoke reflex to clarify some peculiarities.

\section{RESULTS}

\section{Spontaneous activity}

During the preovulatory phase and 5 days after surgery, sustained bursts of spikes, 100 to $200 \mu \mathrm{V}$ in amplitude, from 1.6 to $3.5 \mathrm{~min}$ in duration were recorded at 6 to 15-min intervals on the different parts of the oviduct. The duration and frequency were slightly higher on the ampulla and the ampullaryisthmic junction than on the isthmus. The contractions of the oviducts occurred at intervals of less than $30 \mathrm{sec}$ and were almost simultaneous on the two sides.

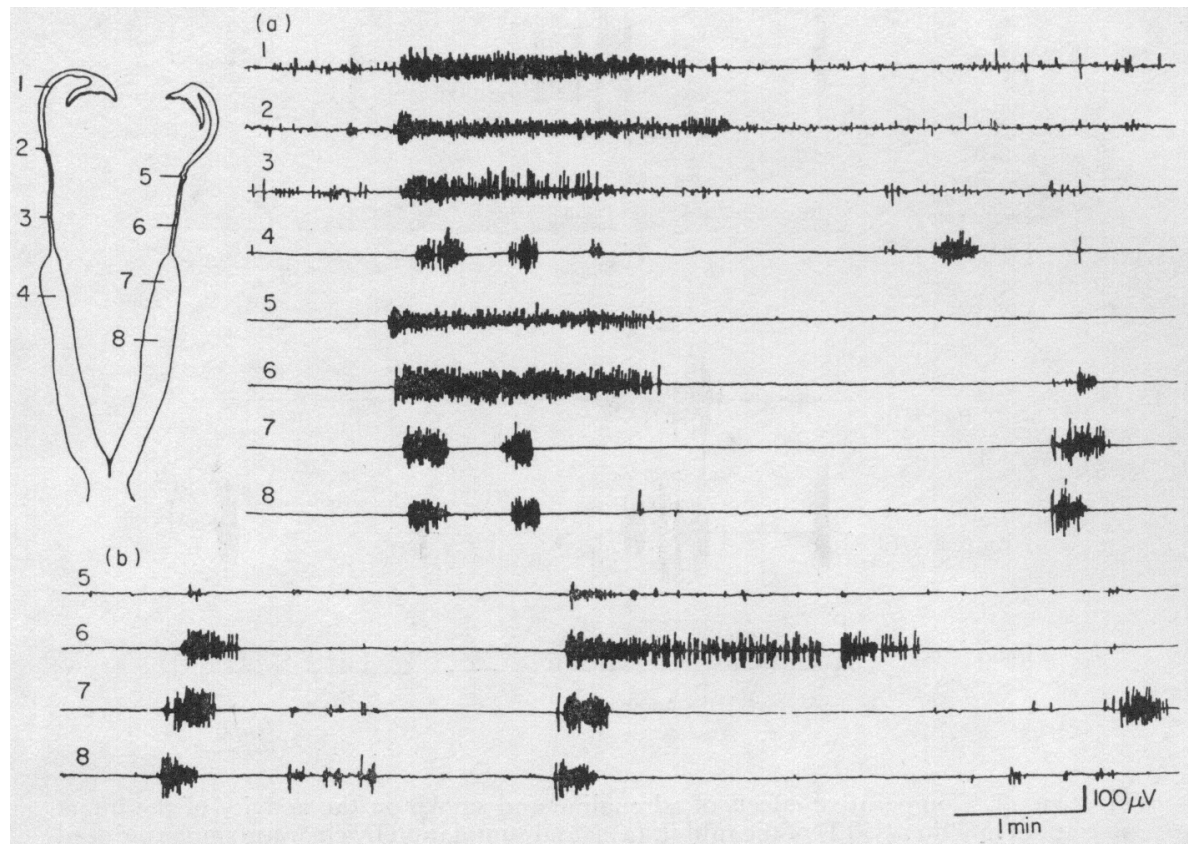

TExT-FIG. 2. Uterotubal activity in an intact rabbit during the preovulatory phase. (a) Sustained bursts of spikes of the oviducts are synchronous on right $(1,2,3)$ and left sides $(5,6)$. Contractions of the uterus $(4,7,8)$ occurred simultaneously. (b) Activation of the lower part of the isthmus (6) subsequent to ascending contractions of the proximal part of the uterus $(7,8)$.

They were usually followed by one or two contractions of the proximal segment of the uterus which took the form of bursts of spikes, 200 to $250 \mu \mathrm{V}$ in amplitude, lasting about $30 \mathrm{sec}$ and recurring at a frequency of 18 to $40 / \mathrm{hr}$ (Text-fig. 2). The pattern of activity of the distal segment of the uterus was similar except that the frequency was 15 to $30 / \mathrm{hr}$. No definite pattern or synchrony of contractions between the two uterine horns was recorded. Bursts of spikes were also observed in the proximal segment of the uterus passing from one electrode site to the other in either direction at a speed of about $5 \mathrm{~cm} / \mathrm{min}$. When such a 
propagation reached the uterotubal junction, an activation of the lower part of the isthmus, lasting $30 \mathrm{sec}$ or more, occurred (Text-fig. 2b). Both the cervix and vagina exhibited short bursts of spikes $(10$ to $20 \mathrm{sec}$ ) which frequently occurred in a series concomitant with those seen on the oviduct (see Table 1).

About $72 \mathrm{hr}$ after the injection of $\mathrm{HCG}$, the activity of the oviduct and the uterus decreased progressively to irregular spikes, $50 \mu \mathrm{V}$ in amplitude, that are characteristic of the luteal phase. Before this, an increase in activity involving the oviduct and the uterus was successively recorded. From 18 to $36 \mathrm{hr}$ after the injection, prolonged contractions of the oviduct occurred at a high frequency, especially on the ampulla. Although this activity then declined, the activity of the proximal segment of the uterus increased from 36 to $38 \mathrm{hr}$. The activity of the cervix slightly decreased $72 \mathrm{hr}$ after HCG administration. No changes were recorded on the vagina.

Table 1. Patterns of contractions recorded from the oviduct, uterus, cervix and vagina of twelve rabbits in various hormonal states

\begin{tabular}{|c|c|c|c|c|c|c|}
\hline & \multicolumn{2}{|c|}{ Oviduct } & \multicolumn{2}{|c|}{ Uterus } & \multirow[b]{2}{*}{ Cervix } & \multirow[b]{2}{*}{ Vagina } \\
\hline & Ampulla & Isthmus & Proximal & Distal & & \\
\hline $\begin{array}{l}\text { Preovulatory phase } \\
\text { Duration (min) } \\
\text { Frequency (per hr) }\end{array}$ & $\begin{array}{c}1 \cdot 6-3.5 \\
4-10\end{array}$ & $\begin{array}{c}1 \cdot 7-3 \cdot 2 \\
3-9\end{array}$ & $\begin{array}{c}0 \cdot 2-0 \cdot 3 \\
18-40\end{array}$ & $\begin{array}{c}0 \cdot 2-0 \cdot 3 \\
15-30\end{array}$ & $\begin{array}{c}0 \cdot 1-0 \cdot 2 \\
3-10\end{array}$ & $\begin{array}{r}0 \cdot 05-0 \cdot 1 \\
3-10^{*}\end{array}$ \\
\hline $\begin{array}{l}\text { After HCG }(72 \mathrm{hr}) \\
\text { Duration (min) } \\
\text { Frequency (per hr) }\end{array}$ & $\begin{array}{c}0 \cdot 3-2 \cdot 0 \\
6-10\end{array}$ & $\begin{array}{c}0 \cdot 1-1 \cdot 3 \\
3-9\end{array}$ & $\begin{array}{c}0 \cdot 1-0 \cdot 2 \\
9-10\end{array}$ & $\begin{array}{c}0 \cdot 1-0 \cdot 2 \\
9-10\end{array}$ & $\begin{array}{l}0 \cdot 1 \\
1-2\end{array}$ & $\begin{array}{c}0 \cdot 05-0 \cdot 1^{*} \\
3-10\end{array}$ \\
\hline $\begin{array}{l}\text { Ovariectomized ( } 7 \text { days) } \\
\text { Duration (min) } \\
\text { Frequency (per hr) }\end{array}$ & $\begin{array}{c}0 \cdot 3 \\
45-65\end{array}$ & - & 二 & - & - & - \\
\hline
\end{tabular}

* As a series of two to five bursts of spikes.

After ovariectomy, the ampulla exhibited short contractions at a high frequency of nearly $\mathrm{l} / \mathrm{min}$. The ampullary-isthmic junction and the isthmus were quiescent. The proximal and distal segments of the uterus and the cervix remained quiet. Some isolated bursts of spikes persisted on the vagina.

\section{Activation of the uterotubal junction}

During the preovulatory phase, the strong response induced by smoke which occurred on both sides of the uterotubal junction seemed to originate from the vicinity of the ampullary-isthmic junction (Text-fig. 3a). A similar response was obtained by 2.5 to $5 \mu \mathrm{g}$ adrenaline or $10 \mu \mathrm{g}$ noradrenaline/kg depending on the individual. The responses of the ampulla were less conclusive; adrenaline sometimes resulted in a short inhibition before activation, but noradrenaline always produced an excitatory response. The distal segment of the uterus, the cervix and the vagina always gave an active response to smoke, adrenaline and noradrenaline. After HCG and ovariectomy, the response was damped on the isthmus and uterus, but that of the ampulla and the vagina remained strong. 
At this time, adrenaline, like noradrenaline, was consistently excitatory for the ampulla. The effects of noradrenaline and smoke were blocked by phentolamine administration and the inhibition of adrenaline on the ampulla during the preovulatory phase disappeared. The proximal and distal segments of the uterus were activated by oxytocin and this activity overflowed to the isthmus from the proximal segment (Text-fig. $3 \mathrm{~b}$ ).

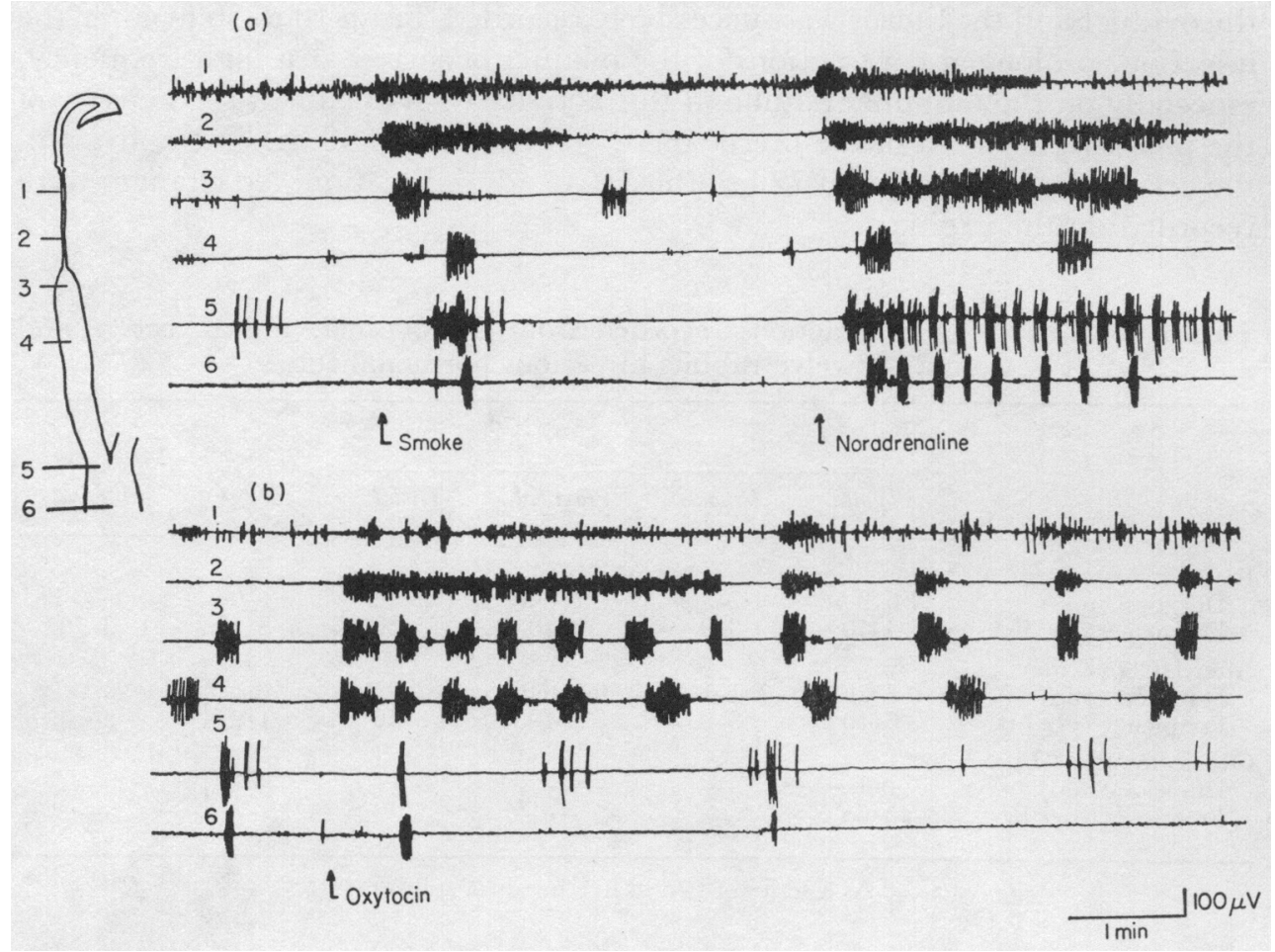

TExT-Fig. 3. Activation of the uterotubal junction in the intact rabbit. (a) Smoke and noradrenaline $(5 \mu \mathrm{g} / \mathrm{kg})$ induced a response beginning on the ampullary-isthmic junction (1). Bursts of spikes were elicited on the cervix (5) and vagina (6) by noradrenaline. (b) The effect of oxytocin was restricted to the uterus $(3,4)$ and overflowed to the isthmus (2).

\section{Effects of section of the uterotubal junction}

Immediately after cutting the uterotubal junction, the activity of the ampulla, the ampullary-isthmic junction and the isthmus was reduced. The activity of the proximal segment of the uterus was subsequently also reduced by 50 to $70 \%$. During the preovulatory phase, the activity of the uterine horn on the side of section sometimes coincided with that of the intact uterine horn, and concomitant contractions of the cervix indicated some propagation from the intact horn to that of the cut side (Text-fig. 4a). In the three rabbits that were injected with oestradiol, the frequency of contractions of the proximal segment of the uterus $48 \mathrm{hr}$ after injection was about twice that of the distal segment on the intact side; the frequency remained constant on the sectioned junction. 
From 48 to $60 \mathrm{hr}$ after injection of HCG, the oviduct and the proximal end of the uterus were strongly active on the side of the intact uterotubal junction, but the isthmus and uterus on the side of section were practically inactive (Text-fig. $4 b)$.

As expected, the activation of the different areas of the genital tract by smoke, adrenergic drugs and oxytocin was abolished on the side of section (Text-fig. 5). The effects of oxytocin were restricted to the uterus, but smoke affected the uterus and occasionally the ampulla. The ampullary-isthmic junction remained almost quiescent and the few contractions no longer seemed co-ordinated with those of the ampulla. Adrenergic drugs affected both sides similarly.

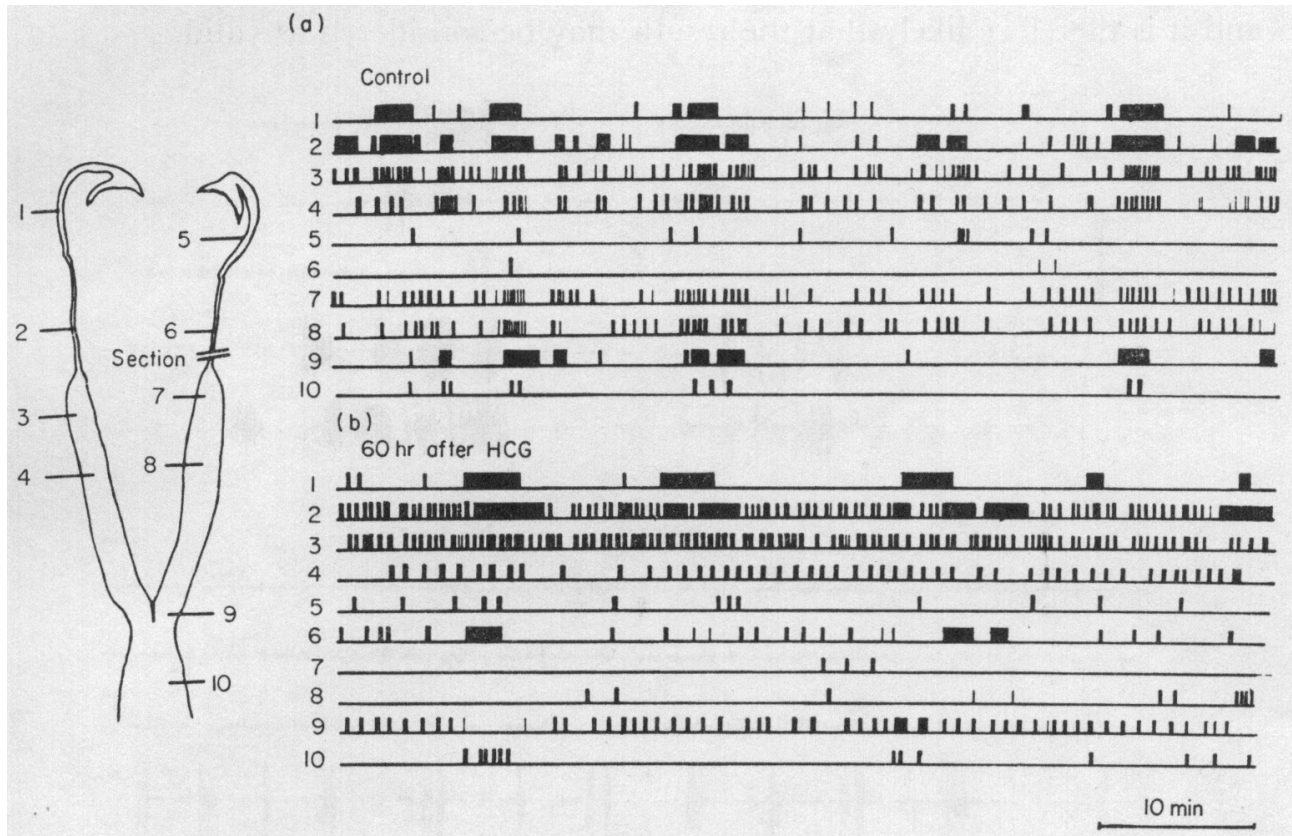

Texr-FIg. 4. Effects of section of the uterotubal junction of the rabbit performed 9 days after implantation of electrodes during the preovulatory phase and $60 \mathrm{hr}$ after injection of 100 i.u. HCG. (a) Reduced activity of the oviduct on the side of section $(5,6)$. Some activity of the uterine horn $(7,8)$ on the cut side was induced from the other horn $(3,4)$ by way of the cervix (9). (b) When the activity of the proximal segment of the uterine horn (3) was increased after HCG, the effects on the same segment (7) on the sectioned side were very much reduced.

After ovariectomy, short bursts of spikes of high frequency $(0.9 / \mathrm{min})$ occurred on the ampulla on the side of section; this was $10 \%$ lower than for the ampulla on the intact side (Text-fig. 6). A notable feature was the strong activation of the region surrounding the uterotubal junction on the cut side by adrenergic drugs and smoke, while the intact junction remained almost silent. The hyperactivity of the cut side disappeared after injection of phentolamine and then only the ampulla exhibited small prolonged bursts of spikes. 


\section{DISCUSSION}

The technique of fixing small macroelectrodes in the muscular layers of the gut (Ruckebusch, 1973) seemed appropriate for chronic experiments on the genital tract with a view to obtaining an overall electrophysiological picture. Care was taken to eliminate any activity evoked by trauma due to surgery especially on the oviduct which is very sensitive under oestrogen dominance. For this reason no recordings were considered for analysis before a stable pattern of bursts of spikes was established with no spiking between their intervals and no major changes in amplitude or frequency. Such a state was obtained about 5 days after surgery and no subsequent encasement of electrodes occurred during the recording period which lasted 3 weeks. After ovariectomy the responsiveness of the individual areas to adrenergic drugs was not only maintained but increased, and it is therefore likely that the results may be considered as valid.

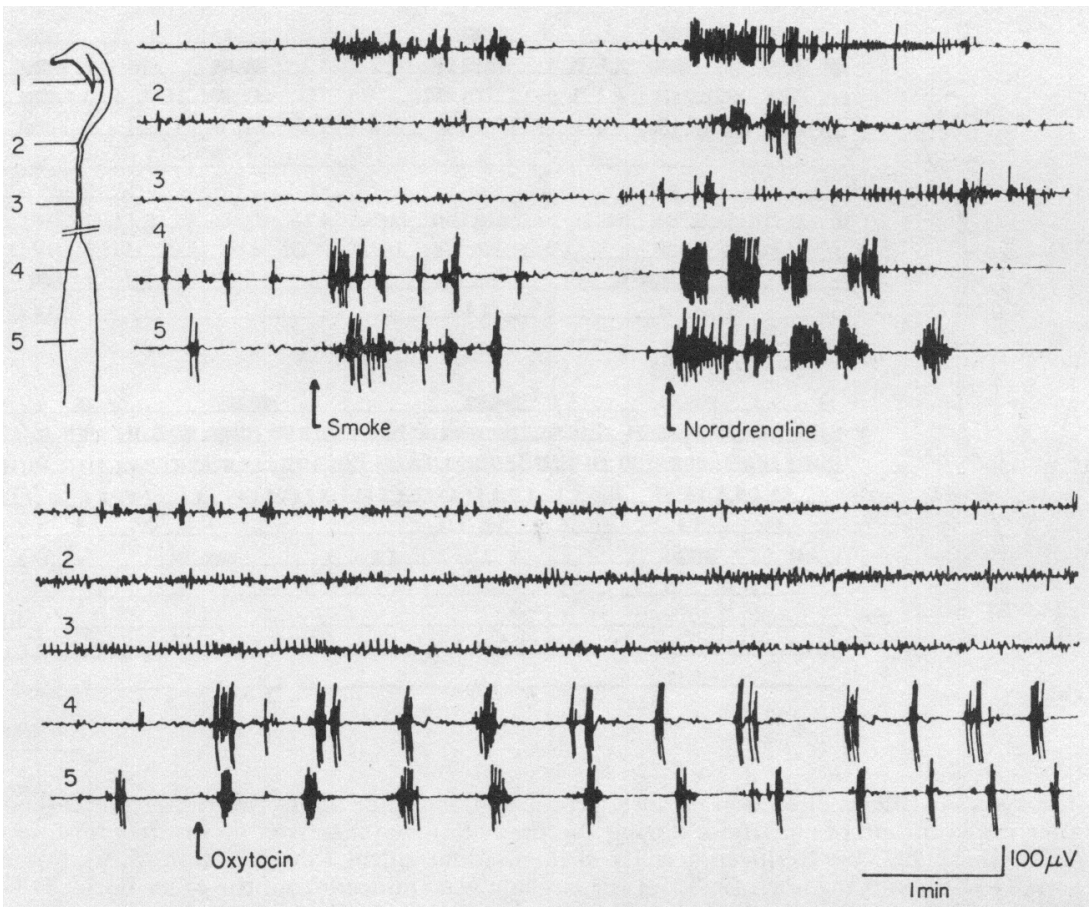

TEXT-FIG. 5. Activation of the uterotubal junction of the rabbit by smoke, adrenergic drugs, and oxytocin after section of the junction and treatment with HCG. Smoke no longer had an effect on the ampullary-isthmic junction (2) but elicited a response on the ampulla (1) and uterus $(4,5)$. Noradrenaline activated the ampulla $(1)$ and uterus $(4,5)$ on the side of section, the ampullary-isthmic junction being unaffected (2). The uterine activity induced by oxytocin $(4,5)$ was not propagated to the isthmus $(3)$.

These findings demonstrate a rhythmic pattern of oviducal activity which precedes activation of the proximal segment of the uterus. After section of the uterotubal junction three major effects occurred. Firstly, there was a decrease in activity on both sides of the section, particularly clearly shown after the injection of HCG. This suggests a positive control of the isthmus on the proximal segment of the uterus although the latter may also affect the former. This hypothesis is reinforced by the fact that this region becomes highly sensitive to 
adrenergic drugs after ovariectomy. The withdrawal of oestrogen may be involved as has been observed for the ampullary-isthmic junction by Boling \& Blandau (1971), and as shown by the effects on the side of section. Since smoke acts via the adrenergic nerves, the responsiveness of the uterotubal junction indicates the importance of this type of innervation to this area.

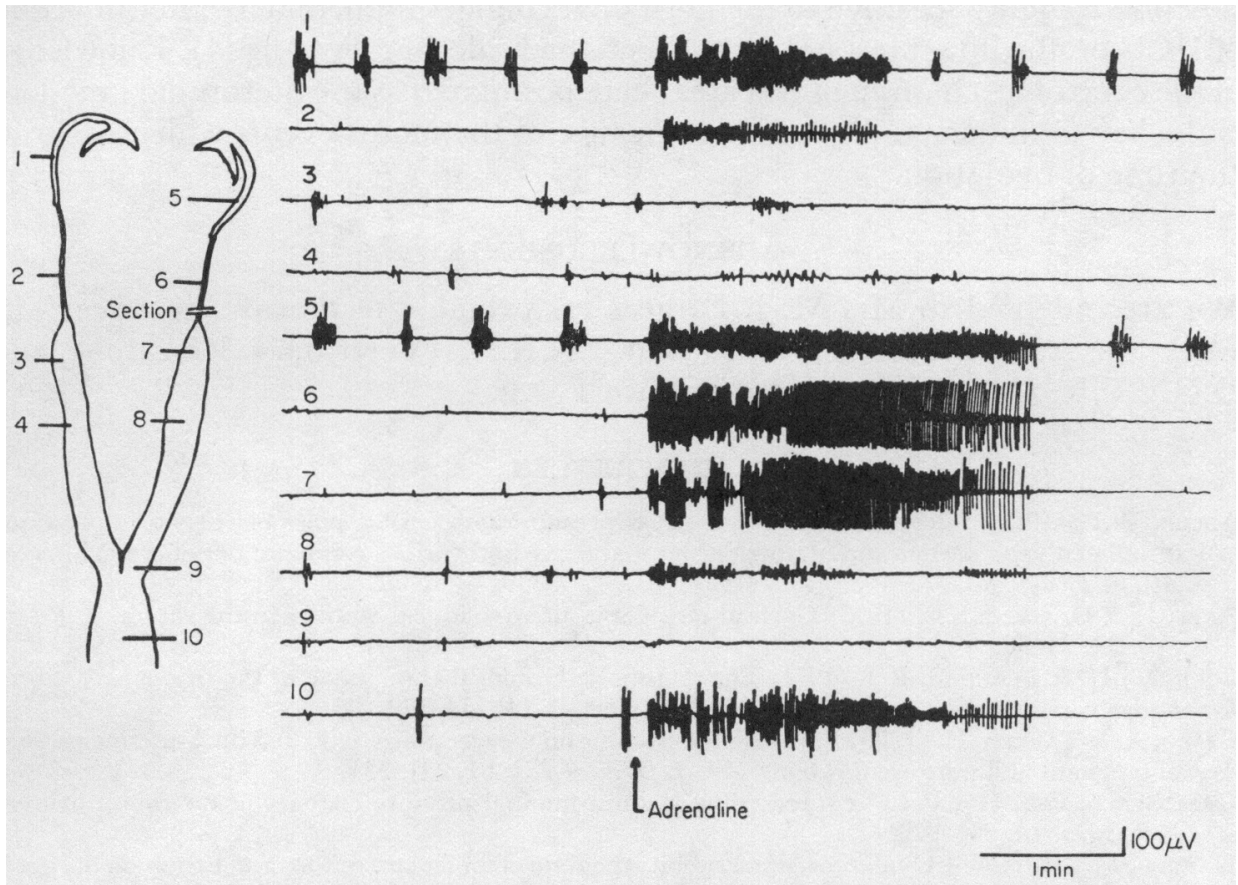

TexT-FIG. 6. Hyperactivity of the oviduct and uterine horns in the ovariectomized rabbit on the side sectioned at the uterotubal junction after injection of adrenaline. Besides the isthmus and proximal segment of the uterus at the cut uterotubal junction $(6,7)$, the ampullae of both intact and cut sides $(1,5)$ and the vagina (10) showed a high responsiveness to adrenaline.

The second point is an expected blocking effect of any transmission of activity across the cut area, either that induced by smoke or adrenergic drugs on the oviduct propagated to the uterus, or that provoked by oxytocin on the uterus propagated to the isthmus. This blocking effect may be consequent upon both a lower sensitivity and a decreased activity of the two regions concerned, each no longer capable of triggering a response in the other. The decrease in the proximal uterine segment on the cut side permits its activation from the intact uterine horn via the distal segment. Such a point is also emphasized in oestrogentreated rabbits in which the frequency of contractions of the proximal segment of the uterus is about twice that of the distal segment but only on the intact side. This would indicate that in normal circumstances the proximal portion of the uterus is dominant with respect to the distal portion. Despite the persistent responsiveness of the ampulla to adrenergic drugs, section appears to deprive it of its role as the site of initiation, or at least to suppress the synchrony of the contractions of the entire genital tract.

The third point is the role of the uterotubal junction in the cyclic changes of motility of the genital tract. As pointed out by Aref \& Hafez (1973), the phasic 
activity of the oviduct and uterus must be co-ordinated to accomplish successful gamete transport. As shown by this study, the ampulla exhibits different patterns according to the hormonal status of the animal: sustained bursts of low frequency ( 4 to $10 / \mathrm{hr}$ ) occur during the preovulatory phase and short regular bursts of high frequency ( 60 to $90 / \mathrm{hr}$ ) are found after coitus. The uterotubal junction is highly sensitive to the hormonal changes immediately after injection of HCG on the intact but not on the sectioned side (see Text-fig. 4). Knowledge of the control mechanism of this area, here postulated as the uterotubal junction, is the key to understanding the significance of the motor events which occur at the time of ovulation.

\section{ACKNOWLEDGMENTS}

We are indebted to Mrs M.-J. Fargeas for valuable technical assistance. The work was supported by grants from I.N.R.A. (Veterinary Research) and D.G.E.E.R. (Ministère de l'Agriculture).

\section{REFERENCES}

ALLEN, W.F. (1929) Effect on respiration, blood pressure and carotid pulse of various inhaled and insufflated vapors when stimulating one cranial nerve and various combinations of cranial nerves. Am. F. Physiol. 88, 117-123.

AReF, I. \& HAfEz, E.S.E. (1973) Cyclical changes in utero-oviducal motility in the rabbit. F. Reprod. Fert. 32, 93-96.

Boling, J.L. \& BLANDAU, R.J. (1971) Egg transport through the ampullae of the oviducts of rabbits under various experimental conditions. Biol. Reprod. 14, 174-178.

CSAPO, A. \& TAKEDA, H. (1965) Effect of progesterone on the electric activity and intra-uterine pressure of pregnant and parturient rabbits. Am. F. Obstet. Gynec. 91, 221-231.

GreenwaLd, G.S. (1963) In vivo recording in intra-luminal pressure changes in the rabbit oviduct. Fert. Steril. 14, 666-670.

HARPER, M.J.K. (1963) Ovulation in the rabbit: the time of follicular rupture and expulsion of eggs in relation to injection of luteinizing hormone. F. Endocr. 26, 307-314.

HARPER, M.J.K. (1966) Hormonal control of transport of eggs in cumulus through the ampulla of the rabbit oviduct. Endocrinology 78, 568-569.

Higgs, G.W. \& MoAwad, A.H. (1974) The effect of ovarian hormones on the contractility of the rabbit oviducal isthmus. Can. 7. Physiol. Pharmacol. 52, 74-83.

HowE, G.R. \& BLACK, D.L. (1973) Autonomic nervous system and oviduct function in the rabbit. I. Hormones and contraction. 7. Reprod. Fert. 33, 425-430.

Longley, W.J., BLAack, D.L. \& CuRrie, G.N. (1968) Oviduct circular muscle response to drugs related to the autonomic nervous system. F. Reprod. Fert. 17, 95-100.

Mattos, C.E.R. DE \& Coutrnho, E.M. (1971) Effects of ovarian hormones on tubal motility of the rabbit. Endocrinology 89, 912-917.

Owman, C., Rosengren, E. \& SJöberG, N.O. (1966) Origin of the adrenergic innervation to the female genital tract of the rabbit. Life Sci. 5, 1389-1396.

Porter, D.G. (1968) The local effect of intra-uterine progesterone upon myometrial activity in the rabbit. F. Reprod. Fert. 15, 437-445.

Ruckebusch, Y. (1973) L'electromyographie globale des muscles lisses à partir d'électrodes chroniques intrapariétales souples. Revue Méd. vét. 124, 1407-1434.

RUCKEBUSCH, Y. \& BAYARD, F. (1975) Motility of the oviduct and uterus of the cow during the oestrous cycle. F. Reprod. Fert. 43, 23-32.

SchofieLd, B.M. (1955) The influence of the ovarian hormones on myometrial behaviour in the intact rabbit. F. Physiol., Lond. 129, 289-304.

SETEKLEIV, J. (1964) Uterine motility of the estrogenized rabbits. III. Response to hypogastric and splanchnic nerve stimulation. Acta physiol. scand. 62, 127-149.

TALo, A. \& BRUNDIN, J. (1971) Muscular activity in the rabbit oviduct; a combination of electric and mechanic recordings. Biol. Reprod. 5, 67-92.

White, S.W., McRitchie, R.J. \& Frankin, D.L. (1974) Autonomic cardiovascular effects of nasal inhalation of cigarette smoke in the rabbit. Aust. F. exp. Biol. 52, 111-126. 